\title{
Corrosion Performance of Austenitic Stainless Steel Bipolar Plates for Nafion- and Room-Temperature Ionic-Liquid-Based PEMFCs
}

\author{
Claudio Mele and Benedetto Bozzini*
}

Dipartimento di Ingegneria dell'Innovazione, Università del Salento, via Monteroni, 73100 Lecce, Italy

\begin{abstract}
In this paper we study the corrosion of AISI 304 austenitic stainless steel PEMFC bipolar plates in aqueous and room-temperature ionic-liquid electrolytes. The anodic potential thresholds and dynamics have been investigated by electrochemical (potentiodynamic and potentiostatic) and in situ spectroelectrochemical methods (visible electroreflectance and VIS-UV spectroellipsometry). We measured the values of damage potentials and we followed the time evolution of corrosion current and reflectivity above and below the pitting potential, obtaining an accurate characterisation of the surface conditions under oxidative attack. The ability of AISI 304 to repassivate in $\mathrm{Cl}^{-}$-containing aqueous solution as well as the amount of residual surface damage have been assessed quantitatively by following electrode reflectivity under applied potential. Outstanding inertness of AISI 304 in [BMP][TFSA] was proved. The results of this work show that low-cost AISI 304 is a promising interconnect material for both Nafion- and RTIL-based PEMFCs.
\end{abstract}

Keywords: PEMFC, bipolar plate, AISI 304, ionic liquid, corrosion, electroreflectance, spectroellipsometry.

\section{INTRODUCTION}

Bipolar plates (BP) are a crucial functional and structural component of PEM fuel cell (FC) stacks. Chiefly, BPs ensure electrical continuity across the stack and support the reactive gas dispensing paths. Graphite can be regarded as the current material of choice for BPs. However, this material is largely sub-optimal for the prospective massproduction and extensive applications in the automotive industry, mainly owing to: brittleness, high thickness, permeability to reactant gases and fabrication costs. Metals thus become an appealing alternative [1-4]. Interest in metallic vs graphite-based BPs is due to the following reasons: (i) higher mechanical strength and toughness; (ii) vanishing permeability to gases; (iii) ease of forming. A list of target highlights of metallic BPs can be found in [5]. The counterpart of the above-listed advantages is however a series of specific drawbacks, essentially related to corrosion resistance; in fact, exposure to FC environment can cause: (i) passivation modes giving rise to an increment of ohmic drop and (ii) release of corrosion products that can damage other FC components, such as gas-diffusion electrodes, ionexchange membranes and catalysts [6].

The principal metallic materials reported in the literature for FC applications are 304 and 316 stainless steel and an Fe8-Cr30 54-C2-Ni (balance): these materials have been tested in a selection of chemical and electrochemical environments $[1,2]$. The published durability test methods include: (i) open circuit potential measurements [7-15], (ii) potentiostatic polarisation $[7-10,13-30]$, (iii) polarisation resistance $[27,31,32]$, (iv) linear-sweep voltammetry [7, 33, 34], (v) $I-V$ and $I-P$ curves and life time tests in fuel-cell

*Address correspondence to this author at the Dipartimento di Ingegneria dell'Innovazione, Università del Salento, via Monteroni, 73100 Lecce, Italy; Tel: +39 0832297621, +390832297290;

E-mail: benedetto.bozzini@unisalento.it assemblies [24, 35-37]. These electrochemical tests have been accompanied by compositional and structural measurements: for relevant details, refer to [2]. Most of the literature studies on BP corrosion have been performed in aqueous electrolytes, representing conditions that are typical of conventional, Nafion-based PEMFCs. Nevertheless, use of room-temperature ionic-liquid (RTIL)-based PEMFC is starting to attract interest, essentially because they do not exhibit the daunting water management problems that complicate practical use of PEMFCs. As far as BP material stability in ionic liquids is concerned, a very limited amount of information is currently available (for a recent review, see [4]). The corrosivity of RTIL media depends on the chemical nature of the cationic and anionic moieties [38] as well as on the presence of water [39], that is unavoidable in PEMFCs. In particular, stainless steel was reported to be highly resistant in anhydrous systems as well as in the presence of traces of water, localized corrosion appearing in the presence of chloride [38, 40].

In this paper we investigate the electrochemical corrosion of AISI 304 austenitic stainless steel in contact with aqueous solutions as 1-butyl-1-methyl-pyrrolidinium bis (trifluoromethylsulfonyl) amide ([BMP][TFSA]) RTIL. In order to simulate an environment typical of the prolonged operation of traditional, Nafion-based PEMFCs, we employed aqueous solutions containing $\mathrm{Cl}^{-}$and $\mathrm{SO}_{4}{ }^{2-}$ ions. The presence of $\mathrm{SO}_{4}{ }^{2-}$ ions is due to Nafion degradation [2], while that of $\mathrm{Cl}^{-}$ions derives from pollution of reactant gases or to the degradation of MEA, since chlorine is employed for its production [12]. The RTIL was used in its pure form in order to emphasise its specific corrosivity. This study is based on electrochemical measurements and in situ visible reflection spectroscopy and spectroellipsometry. The combination of electrochemical and spectroscopic data, recorded simultaneously, allows an insight into corrosion processes at the molecular level, essential for knowledge-based material 
development and for the optimisation of corrosion performance.

\section{EXPERIMENTAL}

Two different electrolytes were employed in this research: an aqueous solutions containing $\mathrm{H}_{2} \mathrm{SO}_{4} 10 \mathrm{mM}$, $\mathrm{HCl} 10 \mathrm{mM}$ and 1-butyl-1-methyl-pyrrolidinium bis(trifluoromethylsulfonyl) amide ([BMP][TFSA]) RTIL. For the aqueous solution, ultrapure water was used as the solvent. The experiments were carried out at room temperature. Electrochemical measurements were performed with an AMEL 5000 programmable potentiostat/galvanostat. A Ventacon cell was employed with a vertical AISI 304 stainless steel disc working electrode (WE) of diameter 5 $\mathrm{mm}$, embedded into a Teflon holder; the counter electrode was a Pt wire loop (area $1.25 \mathrm{~cm}^{2}$ ) concentric and coplanar with the WE disc; the reference electrode $(\mathrm{Ag} / \mathrm{AgCl}(\mathrm{KCl}$ $3 \mathrm{M}$ ) for the aqueous system and Pt for the RTIL), was placed in a separate compartment, with the probe tip placed $3 \mathrm{~mm}$ from the rim of the WE disc. All potentials are reported on the $\mathrm{Ag} / \mathrm{AgCl}$ scale. The metal surface of AISI 304 specimen, prior to measurements, was pre-treated according to the following procedure recommended in [41]: mechanical polishing with emery papers of different grades down to 2400 grit, degreasing with acetone, rinsing with bi-distilled water. At the beginning of each experiment in aqueous solution, the WE was cathodically polarized at $-700 \mathrm{mV}$ for $5 \mathrm{~min}$ to remove surface oxide and to assure reproducibility [7]. Subsequently, the samples, were subjected to anodic potentiodynamic polarisation at a scan rate of $10 \mathrm{mV} \mathrm{s}^{-1}$ and of $0.16 \mathrm{mV} \mathrm{s}^{-1}$.

In situ visible electroreflectance (ER) spectroelectrochemical measurements were carried out with linearly polarised light at $45^{\circ}$ incidence angle. The wavelength was selected with a grating monochromator with a spectral resolution of $7 \mathrm{~nm}$. A photodiode detector was employed. The spectrometer, optics and control electronics were homebuilt. Reflectance measurements were carried out under potentiostatic conditions or by scanning the potential at a rate of $10 \mathrm{mV} \mathrm{s}^{-1}$.

The spectroscopic ellipsometry of AISI 304/solution interface was measured in situ by an UVISEL Ellipsometer (Jobin Yvon). The wavelength range of incident light was 260-830 $\mathrm{nm}$ with the incident angle of $70^{\circ}$.

\section{RESULTS AND DISCUSSION}

\section{Aqueous Electrolyte}

In Fig. (1) a potentiodynamic polarisation plot is reported, measured at a scan rate of $10 \mathrm{mV} \mathrm{s}^{-1}$. The activity, passivity and transpassivity regions can be clearly distinguished. By increasing the voltage, in the activity region the current density (c.d.) increases, in the passivity region it is almost constant, since the specimen surface is covered by an oxide film, and, in the transpassivity region, the c.d. increases rapidly, corresponding to the generation of pits on the surface.

We carried out ERS experiments in order to gain more insightful information on the passive film-forming behaviour. In this investigation we carried out measurements with p-polarised radiation of wavelength $570 \mathrm{~nm}$. This radiation was chosen, since it lies both in the highreflectivity range of steel and in the high efficiency interval of the light source. A voltage step was applied to the electrode, switching the potential from a value corresponding to cathodically protected steel $(-500 \mathrm{mV})$ to a condition in a different range of the voltage-current curve plotted in Fig. (1). The corresponding values of reflectivity were measured as a function of time. Three types of behaviour were observed. On stepping the potential from $-500 \mathrm{mV}$ to a value in the range "a", the following trend of reflectivity was observed during the time: a significant increase due to scattering caused by the activity of metal, a gradual decrease caused by the breakdown of the oxide layer due to active corrosion, tending to reach a nearly asymptotic value. The step of potential from $-500 \mathrm{mV}$ to a value in the passivity region gives rise to an increase of reflectivity, due to the formation of a more reflective passivating oxide layer. The voltage step into the transpassivity region leads to a sudden reduction of reflectivity due to the onset of pitting. The three types of reflectivity trends observed with ERS measures match well with the morphologies found by SEM observations of the sample surfaces after the reflectivity measurements reported above. From the micrographs of Fig. (1), the following conclusions can be drawn. The specimen subjected to a potential in the range "a" shows evidence of uniform corrosion; the step voltage to the range " $b$ " leads to the formation of a passivating oxide; the step in range "c" gives rise to the onset of pitting.

The relationship between the change in reflectivity and the extent of oxidation on the surface has been further examined by recording the reflectivity-potential curve at 570 $\mathrm{nm}$ and the corresponding return voltammetry curve (Fig. 2). During the anodic-going scan the reflectivity-potential curve is almost constant until $850 \mathrm{mV}$ (region c), then it shows a sharp decrease (region d), with a change of slope at $1100 \mathrm{mV}$ (region e). During the reverse potential sweep the reflectivity continues to decrease until a potential of about $1200 \mathrm{mV}$ is reached (region $\mathrm{f}$ ), then it stays almost constant for potentials decreasing to ca. $250 \mathrm{mV}$ (region g), while is shows a recovery of intensity for potentials decreasing to ca. -250 $\mathrm{mV}$ (region $\mathrm{h}$ ) and finally it remains constant (region 1 ) for more cathodic potentials, though at values lower than the initial ones. The observed highly hysteretic reflectivity curve correlates well with the return sweep voltammogram. In fact, a constant c.d. is observed in the passivity range (region c), the regions with decreasing reflectivity correlate with transpassive corrosion (regions $\mathrm{d}$, e and $\mathrm{f}$ ) and the final increase of reflectivity in the reverse scan is related to the repassivation of the steel. The steady-state spectral modification brought about by the application of constant potentials - corresponding to the four typical corrosion conditions highlighted in the discussion of Fig. (1) - was measured by comparing the normalised reflectivity curves derived from in situ spectroellipsometric measurements [42] (Fig. 3). It can be noticed that the large changes in absolute reflectivity at fixed wavelength observed in Figs. $(\mathbf{1}, \mathbf{2})$ correspond to limited changes in the spectral behaviour: in fact qualitative relative reflectivity modifications can be detected only at the highest investigated energies in the presence of scattering by the pits produced at high anodic polarisations. These results emphasise the importance of 

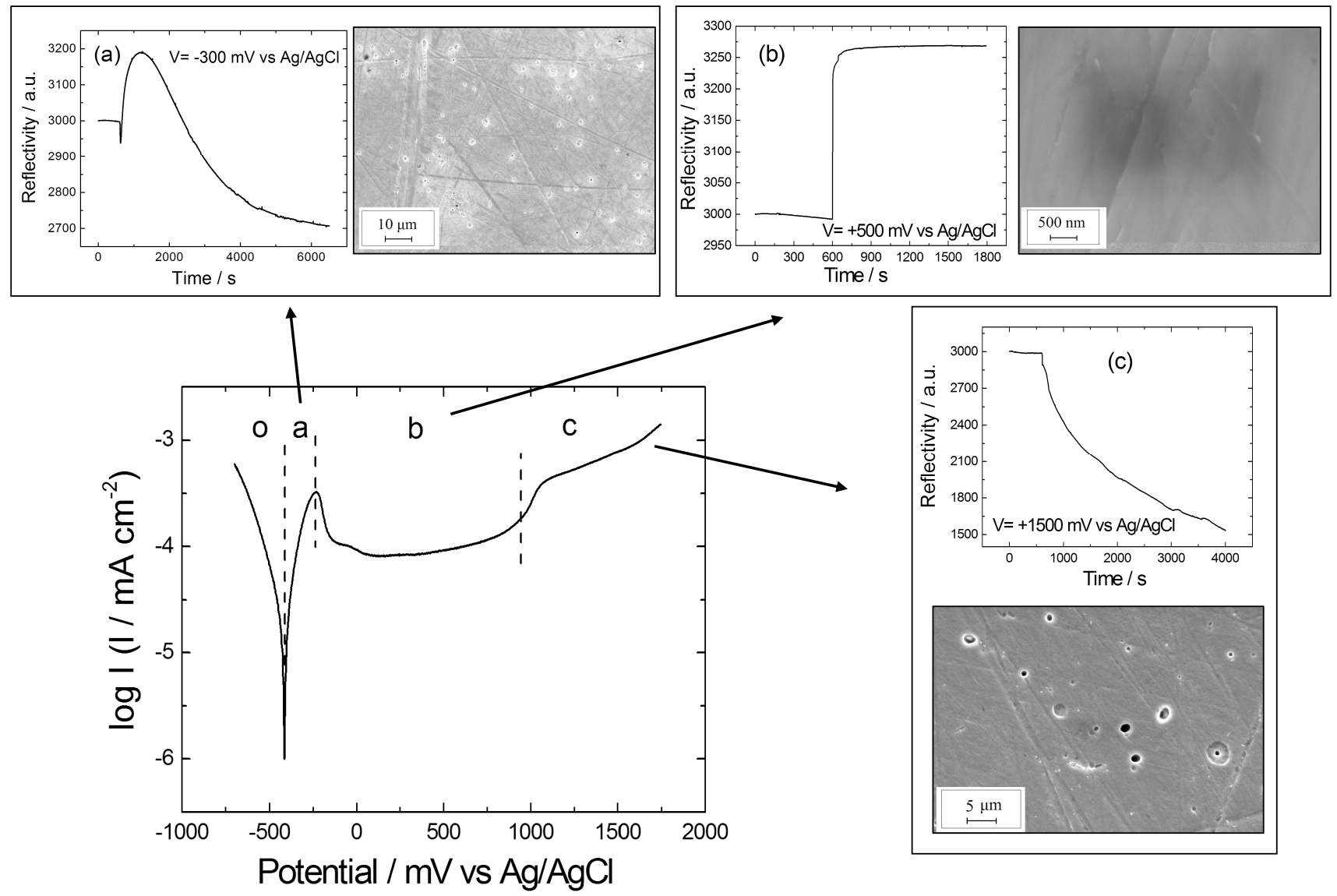

Fig. (1). Anodic polarization curve at $10 \mathrm{mV} \mathrm{s}^{-1}$ of AISI 304 electrode in $\mathrm{H}_{2} \mathrm{SO}_{4} 10 \mathrm{mM}, \mathrm{HCl} 10 \mathrm{mM}$. Insets: reflectivity (wavelength 570 $\mathrm{nm}$ ) as a function of time and SEM micrographs at the end of the measurements at (a) $-300 \mathrm{mV}$, (b) $500 \mathrm{mV}$, (c) $1500 \mathrm{mV}$.

time-dependent, rather than wavelength-dependent measurements for corrosion monitoring of stainless steels.

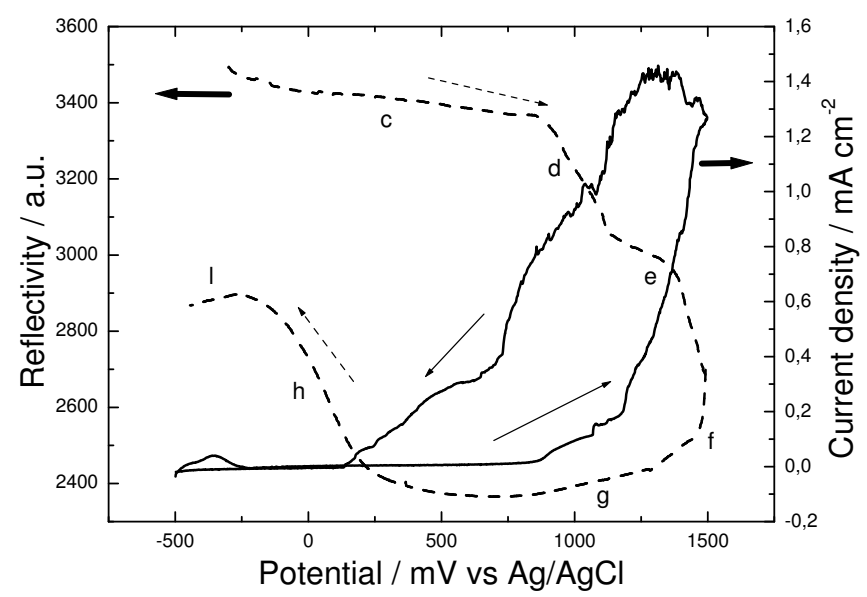

Fig. (2). Reflectivity-potential and current-potential curves of the AISI 304 electrode in electrode in $\mathrm{H}_{2} \mathrm{SO}_{4} 10 \mathrm{mM}, \mathrm{HCl} 10 \mathrm{mM}$. Potential scan rate $10 \mathrm{mV} \mathrm{s}^{-1}$; wavelength $570 \mathrm{~nm}$.

\section{Room-Temperature Ionic-Liquid}

In Fig. (4) the $\mathrm{CV}$ of AISI 304 in [BMP][TFSA] is compared with those measured with glassy carbon (GC) and
Pt. The CV of GC is essentially the same as that reported in $[43,44]$. Anodic and cathodic decomposition of the RTIL occur at about 1.6 and -2.9 V. With AISI 304, the electrochemical window is limited cathodically by catalyzed RTIL decomposition. The small peaks can be due to selective adsorption or reorientation of the RTIL ions - as discussed in $[45,46]$ - as well as to some degree of reactivity of the organic [43]. With $\mathrm{Pt}$ the electrochemical window is limited also anodically by Pt-catalysed RTIL decomposition. These results show an outstanding anodic stability of AISI 304 in the investigated RTIL: in fact lower oxidation current densities were found with stainless steel than with GC and $\mathrm{Pt}$, witnessing lower reactivity of both electrodic material and electrolyte. This shows that AISI 304 is a potentially highly inert material for RTIL-based PEMFC BPs.

In order to investigate more comprehensively the outstanding stability of AISI 304 demonstrated by the quasistationary electrochemical results of Fig. (4) and in order to test the material beyond the normal range of use of fuel cells [2], we measured time-dependent reflectivity at high anodic polarisation, yielding a highly sensitive response to relative changes in surface chemistry and topography caused by corrosion. In Fig. (5) we show c.d. and reflectivity (wavelength $570 \mathrm{~nm}$ ) transients following the application of the potential of $2.5 \mathrm{~V} v s$ Pt (QRE). In both curves a sharp decrease of the measured values is observed reaching an asymptotic value after about one hour. After 36 hours the 
reflectivity is further reduced almost to zero, while the current is essentially constant and very low in absolute value. These results show that, under extreme oxidising conditions, the steel surface forms a rough, but highly protecting layer, incorporating both corrosion products from the metal and oxidation products of the RTIL.

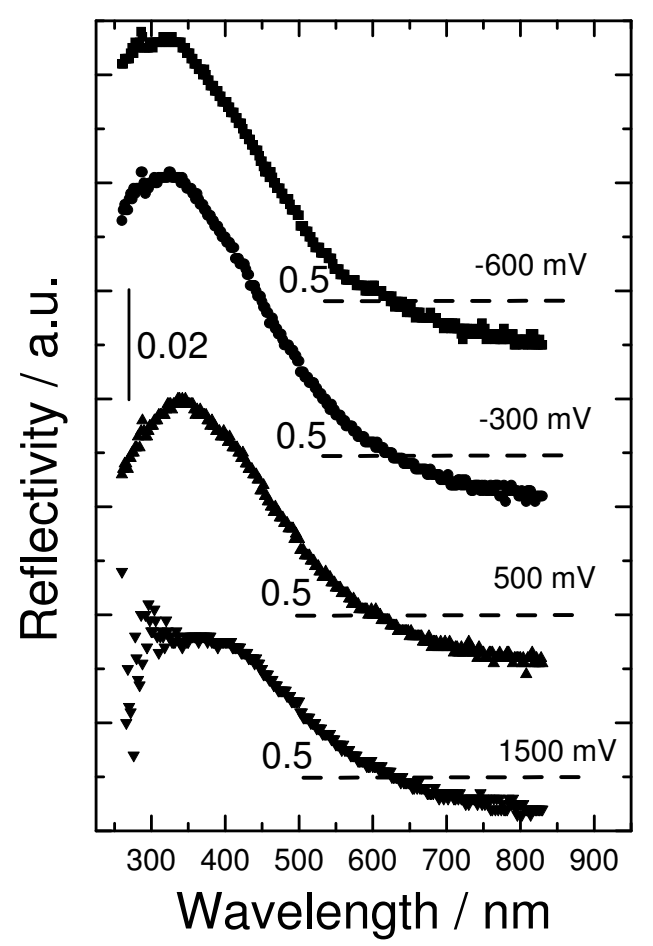

Fig. (3). Normalised reflectivity-wavelength curves of AISI 304 electrode in $\mathrm{H}_{2} \mathrm{SO}_{4} 10 \mathrm{mM}, \mathrm{HCl} 10 \mathrm{mM}$ at different potentials, measured by in situ spectroellipsometry. Incidence angle $70^{\circ}$.

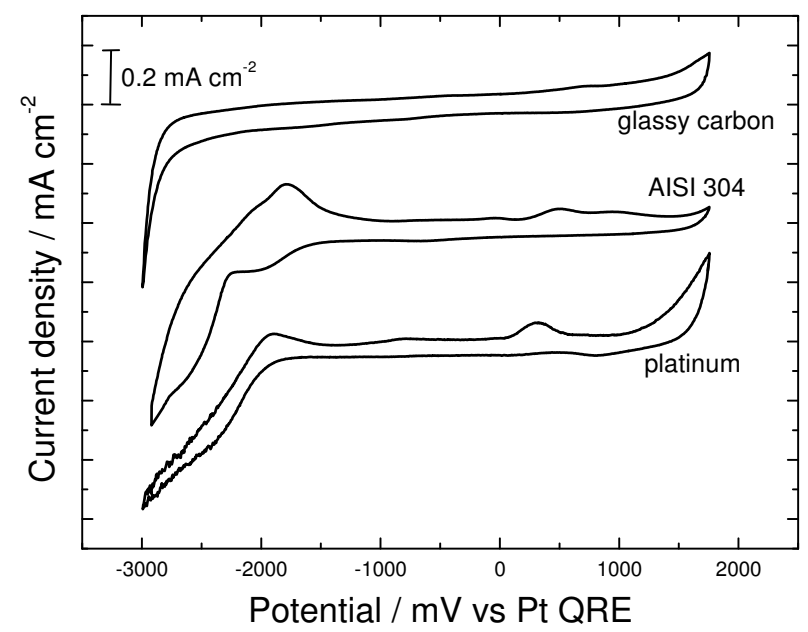

Fig. (4). Cyclic voltammetries (scan rate: $10 \mathrm{mV} \mathrm{s}^{-1}$ ) for glassy carbon, AISI 304 and $\mathrm{Pt}$ in contact with [BMP][TFSA].

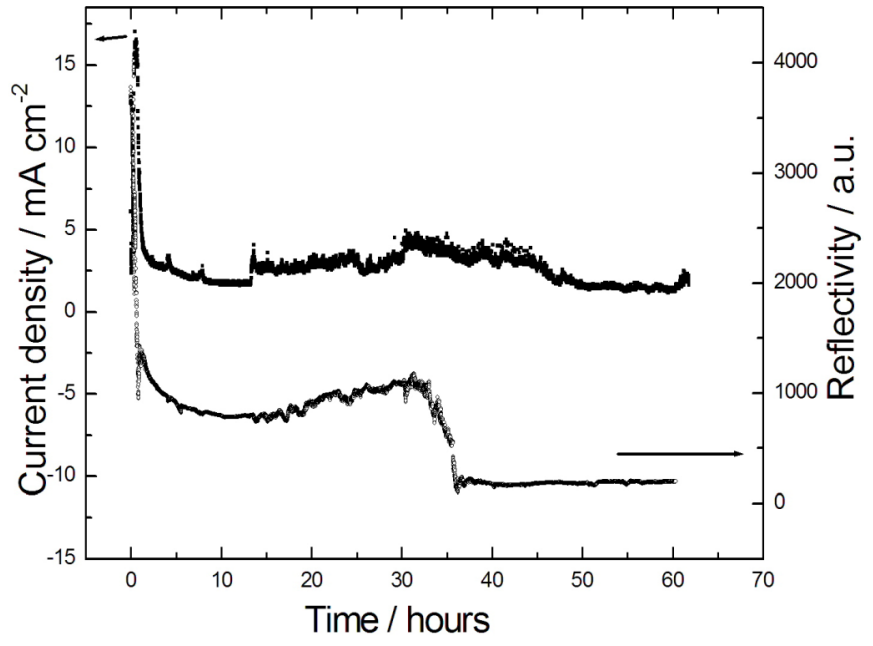

Fig. (5). Reflectivity and current density as a function of time. Applied potential $2500 \mathrm{mV}$; wavelength $570 \mathrm{~nm}$.

\section{CONCLUSIONS}

In this paper we simulated the operating conditions of AISI 304 PEMFC bipolar plates in aqueous and roomtemperature ionic-liquid environments and we followed the damage evolution by in situ visible spectroscopic methods. The pitting behaviour in $\mathrm{Cl}^{-}$-containing sulphate-based aqueous solution and the roughening in [BMP][TFSA] were followed by simultaneous monitoring of current density and reflectivity as a function of applied potential and time. In the aqueous system, the pitting threshold potential was located with much higher accuracy than with an exclusively electrochemical approach and the depassivationrepassivation dynamics was followed in terms of both passive film healing and irreversible roughness buildup. The results show that the investigated material is able to withstand typical PEMFC operating conditions and to selfheal in the case of occasional, unlikely excursions into the damaging range. From the point of view of in situ monitoring, we have assessed quantitatively - on the basis of the comparison between electroreflectance and in situ spectroellipsometric data - that single-wavelength work in the visible range is highly diagnostic of the surface conditions. As far as the RTIL environment is concerned, AISI 304 has been proved to show an outstanding inertia in anodic conditions: both metal dissolution and electrolyte decomposition rates are vanishing for the AISI 304 / [BMP][TFSA] system. In particular, this system exhibits higher inertness than either $\mathrm{GC}$ or Pt, suggesting that this steel is of potential interest not only for PEMFC BPs, but also as an insoluble anode for other electrochemical industrial processes employing RTILs. Electrochemical and spectroelectrochemical tests under high oxidative stress conditions have shown that, after a few hours of operation, AISI 304 does tend to roughen, but it exhibits a negligible corrosion rate, confirming the excellent anodic performance of this material combination also under possible incidental conditions.

\section{ACKNOWLEDGEMENT}

Declared none. 


\section{CONFLICT OF INTEREST}

Declared none.

\section{REFERENCES}

[1] Bozzini, B.; Sgura, I. A Mathematical Model for the Corrosion of Metallic Bipolar Plates in PEM Fuel Cells: Numerical and Experimental Issues. SIAM. J. Appl. Math., 2009, 70, 579-599.

[2] Mele, C.; Bozzini, B. Localised corrosion processes of austenitic stainless steel bipolar plates for polymer electrolyte membrane fuel cells. J. Power Sources, 2010, 195, 3590-3596.

[3] Bozzini, B.; Mele, C.; Gianoncelli, A.; Kaulich, B.; Kiskinova, M.; Prasciolu, M. In situ X-ray spectromicroscopy study of bipolar plate material stability for nano-fuel-cells with ionic-liquid electrolyte. Microelectr. Eng., 2011, 88, 2456-2458.

[4] Bozzini, B.; Gianoncelli, A.; Kaulich, B.; Kiskinova, M.; Mele, C.; Prasciolu, M. Corrosion of Ni in 1-butyl-1-methyl-pyrrolidinium bis (trifluoromethylsulfonyl) amide room-temperature ionic liquid: an in situ X-ray imaging and spectromicroscopy study. Phys. Chem. Chem. Phys., 2011, 13, 7968-7974.

[5] Tawfik, H.; Hung, Y.; Mahajan, D. Metal bipolar plates for PEM fuel cell - a review. J. Power Sources, 2007, 163, 755-767.

[6] Mehta V, Cooper JS. Review and analysis of PEM fuel cell design and manufacturing. J. Power Sources, 2003, 144, 32-53.

[7] Wang, Y.; Northwood, D.O. Effects of $\mathrm{O}_{2}$ and $\mathrm{H}_{2}$ on the corrosion of SS316L metallic bipolar plate materials in simulated anode and cathode environments of PEM fuel cells. Electrochim. Acta. 2007, 52, 6793-6798.

[8] Silva, R.F.; Franchi, D.; Leone, A.; Piloni, L.; Masci, A.; Pozio, A. Surface conductivity and stability of metallic bipolar plate materials for polymer electrolyte fuel cells. Electrochim. Acta., 2006, 51, 3592-3598.

[9] Tian, R.J.; Sun, J.C.; Wang, L. Plasma-nitrided austenitic stainless steel $316 \mathrm{~L}$ as bipolar plate for PEMFC. Int. J. Hydrogen Energy, 2006, 31, 1874-1878.

[10] Iken, H.; Basseguy, R.; Guenbour, A.; Bachir, A.B. Classic and local analysis of corrosion behaviour of graphite and stainless steels in polluted phosphoric acid. Electrochim. Acta., 2007, 52, 2580-2587.

[11] Lafront, A.M.; Ghali, E.; Morales, A.T. Corrosion behavior of two bipolar plate materials in simulated PEMFC environment by electrochemical noise technique. Electrochim. Acta., 2007, 52, 5076-5085.

[12] Pozio, A.; Zaza, F.; Masci, A.; Silva, R.F. Bipolar plate materials for PEMFCs: A conductivity and stability study. Int. J. Power Sources, 2008; 179: 631-639.

[13] Fu, Y.; Hou, M.; Xu, H.; Hou, Z.; Ming, P.; Shao, Z.; Yi, B. Agpolytetrafluoroethylene composite coating on stainless steel as bipolar plate of proton exchange membrane fuel cell. J. Power Sources, 2008, 182, 580-584.

[14] Pozio, A.; Silva, RF.; Masci, A. Corrosion study of SS430/Nb as bipolar plate materials for PEMFCs. Int. J. Hydrogen Energy, 2008, 33, 5697-5702.

[15] Yu, H.; Yang, L.; Zhu, L.; Jian, X.; Wang, Z.; Jiang, L. Anticorrosion properties of Ta-coated 316L stainless steel as bipolar plate material in proton exchange membrane fuel cells. $J$. Power Sources 2009, 191, 495-500.

[16] Li, M.C.; Zeng, C.L.; Luo, S.Z.; Shen, J.N.; Lin, H.C.; Cao, C.N. Electrochemical corrosion characteristics of type 316 stainless steel in simulated anode environment for PEMFC. Electrochim. Acta., 2003, 48, 1735-1741.

[17] Wang, H.; Sweikart, M.A.; Turner, J.A. Stainless steel as bipolar plate material for polymer electrolyte membrane fuel cells. $J$. Power Sources, 2003, 115, 243-251.

[18] Lee, S.J.; Huang, C.H.; Lai, J.J.; Chen, Y.P. Corrosion-resistant component for PEM fuel cells. J. Power Sources 2004, 131, 162168 .

[19] Wang, H.; Turner, J.A. Ferritic stainless steels as bipolar plate material for polymer electrolyte membrane fuel cells. J. Power Sources, 2004, 128, 193-200.

[20] Wang, H.; Brady, M.P.; More, K.L.; Mayer, H.M, Turner, J.A. Thermally nitrided stainless steels for polymer electrolyte membrane fuel cell bipolar plates - Part 2: Beneficial modification of passive layer on AISI446. J. Power Sources 2004, 138, 79-85.
Wang, H.; Brady, M.P.; Teeter, G.; Turner, J.A. Thermally nitrided stainless steels for polymer electrolyte membrane fuel cell bipolar plates - Part 1: Model Ni-50Cr and austenitic 349 (TM) alloys. $J$. Power Sources, 2004, 138, 86-93.

[22] Jayaraj, J.; Kim, Y.C.; Kim, K.B.; Seok, H.K.; Fleury, E. Corrosion studies on Fe-based amorphous alloys in simulated PEM fuel cell environment. Sci. Technol. Adv. Mater, 2005, 6, 282-289.

[23] Wang, Y.; Northwood, D.O. An investigation of the electrochemical properties of PVD TiN-coated SS410 in simulated PEM fuel cell environments. Int. J. Hydrogen Energy, 2007, 32, 895-902.

[24] Davies, D.P.; Adcock, P.L.; Turpin, M.; Rowen, S.J. Bipolar plate materials for solid polymer fuel cells. J. Appl. Electrochem., 2000, 30, 101-105.

[25] Ren, Y.J.; Zeng, C.L. Corrosion protection of 304 stainless steel bipolar plates using $\mathrm{TiC}$ films produced by high-energy micro-arc alloying process. J. Power Sources, 2007, 171, 778-782.

[26] Ho, W.Y.; Pan, H.J.; Chang, C.L.; Wang, D.Y.; Hwang, J.J. Corrosion and electrical properties of multi-layered coatings on stainless steel for PEMFC bipolar plate applications. Surf. Coat. Technol., 2007, 202, 1297-1301.

[27] Cho, K.H.; Lee, W.G.; Lee, S.B.; Jang, H. Corrosion resistance of chromized 316L stainless steel for PEMFC bipolar plates. J. Power Sources, 2008, 178, 671-676.

[28] Chung, Ch-Y.; Chen, Sh-K.; Chiu, P-J.; Chang, M-Hs.; Hung, TTs.; Ko, Ts-H. Carbon film-coated 304 stainless steel as PEMFC bipolar plate. J. Power Sources, 2008, 176, 276-281.

[29] Nikam, V.V.; Reddy, R.G.; Collins, S.R.; Williams, P.C.; Schiroky, G.H.; Henrich, G.W. Corrosion resistant low temperature carburized SS 316 as bipolar plate material for PEMFC application. Electrochim. Acta., 2007, 53, 2743-2750.

[30] Kumagai, M.; Myung, S.T.; Kuwata, S.; Asaishi, R.; Yashir, H. Corrosion behavior of austenitic stainless steels as a function of $\mathrm{pH}$ for use as bipolar plates in polymer electrolyte membrane fuel cells. Electrochim. Acta, 2008, 53, 4205-4212.

[31] Lee, S.J.; Huang, C.H.; Chen, Y.P. Investigation of PVD coating on corrosion resistance of metallic bipolar plates in PEM fuel cell. J. Mater. Process. Technol., 2003, 140, 688-693.

[32] Wang, Y.; Northwood, D.O. Growth mechanisms for SiC-AlN solid solution crystals prepared by combustion synthesis. J. Power Sources, 2006, 163, 501-508.

[33] Wang, Y.; Northwood, D.O. An investigation into TiN-coated 316L stainless steel as a bipolar plate material for PEM fuel cells. J. Power Sources, 2007, 165, 293-298.

[34] Wang, H.; Turner, J.A. SnO2 : F coated ferritic stainless steels for PEM fuel cell bipolar plates. J. Power Sources, 2007, 170, 387394.

[35] Hung, Y.; El-Khatib, K.M.; Tawfik, H. Corrosion-resistant lightweight metallic bipolar plates for PEM fuel cells. J. Appl. Electrochem., 2005, 35, 445-447.

[36] Hung, Y.; El-Khatib, K.M.; Tawfik, H. Testing and evaluation of aluminum coated bipolar plates of pern fuel cells operating at 70 degrees C. J. Power Sources, 2006, 163, 509-513.

[37] Wang, S.H.; Peng, J.; Lui, W.B.; Zhang, J.S. Performance of the gold-plated titanium bipolar plates for the light weight PEM fuel cells. J. Power Sources, 2006, 162, 486-491.

[38] Uerdingen, M.; Treber, C.; Balser, M.; Schmitt, G.; Werner, C. Corrosion behaviour of ionic liquids. Green Chem., 2005, 7, 321329.

[39] Bermudez, M.D.; Jimenez, A.E.; Martınez-Nicolás G. Study of surface interactions of ionic liquids with aluminium alloys in corrosion and erosion-corrosion processes. Appl. Surf. Sci., 2007, 253, 7295-7299.

[40] Reddy, R.G.; Zhang, Z.J.; Arenas, M.F.; Blake, D.M. Thermal stability and corrosivity evaluations of ionic liquids as thermal energy storage media. High Temp. Mater. Process, 2003, 22, 8795.

[41] Hermas, A.A.; Morad, M.S. A comparative study on the corrosion behaviour of 304 austenitic stainless steel in sulfamic and sulfuric acid solutions. Corros. Sci., 2008, 50, 2710-2717.

[42] Fujiwara, H. Spectroscopic Ellipsometry: Principles and Applications, Wiley: England, 2007.

[43] MacFarlane, D.R.; Meakin, P.; Sun, J.; Amini, N.; Forsyth, M. Pyrrolidinium imides: a new family of molten salts and conductive plastic crystal phases. J. Phys. Chem. B., 1999, 103, 4164-4169. 
[44] Bozzini, B.B.; Bund, A.; Busson, B.; Humbert, C.; Ispas, A.; Mele, C.; Tadjeddine, A. An SFG/DFG investigation of $\mathrm{CN}$ - adsorption at an $\mathrm{Au}$ electrode in 1-butyl-1-methyl-pyrrolidinium bis(trifluoromethylsulfonyl) amide ionic liquid. Electrochem. Commun., 2010, $12,56-60$
[45] Sur, U.K, Lakshminarayanan, V. A study of the hydrophobic properties of alkanethiol self-assembled monolayers prepared in different solvents. J. Electroanal. Chem., 2004, 565, 343-350.

[46] Zawisza, I., Bin, X., Lipkowski, J. Spectroelectrochemical studies of bilayers of phospholipids in gel and liquid state on $\mathrm{Au}(111)$ electrode surface. Bioelectrochemistry, 2004, 63, 137-142.

Received: May 2, 2012

(C) Mele and Bozzini; Licensee Bentham Open.

This is an open access article licensed under the terms of the Creative Commons Attribution Non-Commercial License (http://creativecommons.org/licenses/by$\mathrm{nc} / 3.0 /$ ) which permits unrestricted, non-commercial use, distribution and reproduction in any medium, provided the work is properly cited. 